Remarks. - Cases of this kind are very rare; it is, therefore, of the utmost importance that they shonld be recorded, so that all medical men may know that such cases do sometimes occur. Ignorance upon this point is calculated to do much mischief, both to the profession and the public. The feelings of the relations may be severely tried, and the reputation of the surgeon seriously imperilled, by an expression of opinion as to the non-advisability of surgical interference. The slightest consideration renders it evident that there is no choice but between continually increasing suffering, leading to ultimate death, and the effort to restore the natural channel by surgical means.

Connaught-square, April, 1860.

\section{d. allitror}

OF THE PRACTICE OF

\section{MEDICINE AND SURGERY IN THE}

\section{HOSPITALS OF LONDON.}

Nulla est alia pro certo nosceridi via, nisi quam pluximas et morborum et dissectionum historias, tam aliorum proprias, collectas habere et inter se comparare.-Morgagn.' De Sed. et Caus. Morb., lib. 14. Procmium.

\section{GUY'S HOSPITAL.}

EMBOLON IN THE IEFT CAROTID AND CEREBRAL ARTERIES, AND ALSO IN THOSE OF THE SPLEEN AND FIDNEYS; FATAL RESULT.

(Under the care of Drs. AdDison and REEs.)

A FEW years back Virchow described a disease of the circalation under the name of emboli, signifying the detachment of some of the particles of fibrinous concretions or solid bodies formed in the heart or great vessels, whence they are carried along with the current of the blood, and finally obstruct some of the smaller or secondary branches of the vascular system. Such obstruction would naturally give rise to a certain set of symptoms according to the situation in which it might occur. The conditions producing it, however, are referable to gangrenous inflammation of the veins, organic affections of the left side of the heart, and atheromatous degeneration of the large arterial trunks. There are, probably, some other causes; but of the three mentioned, the second would seem to be the most common, and is observed chiefly in connexion with the cardiac mischief arising from rheumatism. The third, perhaps, ranks next in frequency.

Curiously enough, the three cases of the disease which we record were those in which rheumatisu apparently played a prominent part; and, if our space permitted, we could have added a few cases wherein no symptoms of embolon were present, but serving simply as illustrations of the class of cases most likely to give rise to the disease.

It is on the borders of the mitral valve that these fibrinous concretions chiefly grow; and as their adhesion is oftentimes of the slightest possible character, the activity of the circulation alone proves sufficient for their detachment and carriage along the current of the blood, until the calibre of the vessel becomes too small to permit of their passing any further.

The fact has also been pointed out, that if the patient does not succumb from the first attack, he is liable to do so from the second or third; but occasionally they may be multiplied. If it be admitted that Dr. Parkes's patient is an example of the disease in question, it might be said there were frequent recurrences of the symptoms; but the patient ultimately recovered. Dr. Farre's patient is slowly improving, and the state of the patient's heart leaves no doubt of the correctness of the diagnosis.

It is impossible to say that any one set of arteries more than another is liable to be plugged up, as it manifestly depends upon the course which the floating body may take. The carotid and cerebral are, perhaps, the most frequently found in that condition ; then come those of the extremities ; and, finally, those of the kidney and spleen. Some of these are clearly verified in the annexed case.
It is a noteworthy fact, that if the collateral circulation becomes established, the general disturbance is but temporary. It is otherwise when it fails, for then we encounter one of the forms of gangrene, dry or moist, partial or general, according to the trunk involved. These points are well understood in diseases of the bloodvessels, but they have hitherto not been given sufficient prominence. Pott's gangrene, described so many years back, is clearly due to total arrest of the circulation in minute arterial twigs, the result of atheromatous or, more likely, calcareous degeneration in their coats in the aged.

The following case (for the notes of which we are indebted to Mr. John Henry Gatton, clinical clerk) will be found one of extreme interest, and an excellent example of the disease under consideration :-

Jane $\mathrm{P}-$, aged fourteen, was admitted Nov. 2nd, 1859, into Lydia ward, under the care of Dr. Addison. She was a pale, strumous-looking girl, with widely-dilated pupils. Menstruation had not commenced, and there was no mammary development. Her mother stated that, though delicate, she had never had any illness till eight weeks before admission, when her joints became painful and swollen, the smaller joints being affected as well as the knees, ankles, \&c. A week before she entered she became worse and began to lose flesh. On admis. sion, her knees and ankles were affected, and a large systolic bruit was audible over the mitral valve, with abnormal rough ness over the aortic valves. Præcordial dulness was slightly increased; respiratory sounds normal. No history of previous rheumatism. The symptoms were attributed by Dr. Addison to sub-acute rheumatism. Ordered three grains of iodide of potassium and twenty minims of tincture of hyoscyamus, in peppermint julep, three times a day. A blister over the sternum.

Nov, 4th.-Ordered four grains of calomel at once, and a senna draught with twenty minims of wine of colchicum five hours afterwards.

11th. - Some improvement; pains less. Ordered two grains of iodide of potassium three times a day.

On the 19th, the case came under the care of Dr. Rees. Return of pain from cold. To have five grains of Dover's pill every night, and decoction of cinchona with soda twice a day. 21st. - Right knee contracted and painful. To be rubbed with mercurial ointment.

30 th. - Knee better, but the patient complains of general pains. Pulse quick; skin hot.

Dec. 4th. - She is very ill; unable or unwilling to speak or protrude the tongue; pain in the knees and ankles; memory slightly affected. Ordered one grain of opium every eight hours, and six ounces of brandy.

5th.-Pains and taciturnity continued; pupils natural ; perspiration profuse; tongue white, thickly furred; urine found to be albuminous. Ordered three grains of calomel and one of opium at bedtime.

6th. - In great pain if moved; has complete loss of motion of right arm and leg; no anæsthesia; feet peculiarly inverted; facial paralysis on the right side also noticed.

8th. - She is more cheerful, and the pulse stronger.

9th. -Action of facial muscles continues stronger on the left than on the right side; no double vision; right pupil silghtly more dilated; can flex the right forearm after it has been ex. tended, and move her fingers; can also move the right leg; tongue clean, protrudes towards the right side of the median line; pulse 116. (Dr. Rees diagnosed the occurrence of "embolon" in one of the cerebral arteries, and also-from the "bloody urine"-in the kidney.)

14th. - Bowels confined. Ordered suitable aperient medicine, and a blister to the nape of the neck. Urine still bloody; specific gravity 1015 .

18th. - Much improved; paralysis gradually diminishing. Ordered a mutton chop.

She then continued improving till the $27 \mathrm{th}$, when vomiting occurred, and she became rapidly worse, losing her speech, and at times her consciousness; paralysis also returning. On the 2nd of January diarrhcea had supervened, and she was ordered by Dr. Barlow an enema of starch and opium, and half an ounce of a mixture, twice a day, containing half a grain of strychnine to eight ounces of water. She continued gradually sinking, incapable of motion, and losing all consciousness, till the 9th of January, when she died at four o'clock A. M.

Post-mortem examination. - Body extremely emaciated and ill-developed. On examining the brain, the left carotid artery at its base was completely obstructed by a fibrinous plug, which extended a short distance into the middle cerebral artery. The left corpus striatum and thalamus opticus were soft, and, on microscopical examination by Dr. Wilks, pre. 
sented numerous granular masses. Pericardium healthy. Mitral valve covered with a thick mass of vegetations, to which coagula were adherent. Spleen large, congested at one end, and firm, the section showing a mass of minute extravasation. The kidneys contained several fibrinous masses in various stages; their structure full of minute extravasations.

\section{UNIVERSITY COLLEGE HOSPITAL.}

EMBOLON IN THE CEREBRAL ARTERIES, PRODUCING HEMIPLEGIA, IN A CASE OF DISEASE OF THE HEART FROM RHEUMATISII ; RECOVERY.

(Under the care of Dr. PARKES.)

THE symptoms of impaired nervous power in the following case are very different from those which are usually encountered in paralysis depending upon sanguineous effusions or softening of the brain; for the attack occurred suddenly, whilst the patient was in the hospital, and every vestige of the palsy had disappeared on the fourth day, leaving behind morbidly-acute sensation in the right ear. Now, in cases of even very slight congestion of the brain, a patient may not lose consciousness, and may have a temporary paralysis; but it is seldom that the symptoms so totally disappear in the short time mentioned in the present instance. For a week he now had slight recurring attacks of paralysis every morning on the left side of the body; it then became persistent, and he finally left the hospital improved. The case was suspected to be one of embolon; and although the symptoms are not very clear, we include it in the same category with the others.

The following notes are a brief abstract from the hospital books furnished us by Mr. W. Murray, the physician's assistant:-

Charles S_- aged thirty-six; has been subject to attacks of rheumatism, and has, during the paroxysms, had cardiac affections. About May 1st, 1858, he began to feel weak and languid, and suffered frequently from præcordial pain. On June 1st, 1859, he was admitted into hospital, in rather a weak state, with considerable pain at the epigastrium and uneasiness after eating. The chest is barrel-shaped, with slight bulging in the cardiac region; the lungs are healthy; the heart's area of dulness is too large; a murmur with first sound is heard at the base, of greatest intensity over the second right costal cartilage; another murmur with first sound is heard loudest at the apex; (aortic obstruction and mitral regurgitation diagnosed ;) no diastolic murmurs.

June 3rd, 1859. - Eight A.M. : He was seized with pain in the head, loss of power in the limbs, and loss of speech. When the physician's assistant saw him, he was lying on his right side, with the legs drawn up; speech very difficult; countenance very anxious, and bathed in a cold perspiration. The mouth was drawn to the left side; right eyelids partially paralysed; pupils contracted equaliy; sees best with the right eye, and hears best with the right ear; dysphagia; fluid returning through the nares; total loss of sensation and motion of the right arm; no rigidity; the left arm unaffected; loss of sensation, \&c., of the right side of the chest; the lower extremities unaffected; the urine passed freely; healthy. He was ordered calomel with croton oil.

6th. - Every symptom of paralysis has disappeared; in fact, the right ear is too sensitive.

14th.-Has had each morning a short attack of paralysis on the right side.

18th. - The right side quite perfect; the left arm has become slightly paralysed; and the left ear has become affected.

From this time he improved, and left the hospital in July, with his urine slightly albuminous.

\section{ST. BARTHOLOMEW'S HOSPITAL.}

EMBOLON IN THE CEREBRAL ARTERIES, FOLLOWED BY HEMIPLEGIA ; EXTENSIVE MITRAL VALVULAR DISEASE FROM RHEUMATISM ; IMPROVEMENT.

(Under the care of Dr. FARRE.)

WHEN the infarctus occurs in the brain, it is said to usually occasion yellow softening; but the rapidity of the functional disturbance, as in the following case, simulates an attack of apoplexy. Here, however, although the symptoms perhaps do not differ from a case of cerebral hæmorrhage or acute soften. ing, the attack was followed by hemiplegia without loss of intelligence or of speech, and slow improvement is going on. From the state of the mitral valve, it is probable there will be a recurrence of the mischief at a later period. A case has been recorded by Schützenberger, in which numerous slightly attached irregular vegetations were present on the mitral valve, and many also were found loose in the cavity of the ventricle.

Henry $\mathrm{S}-$, a butcher's boy, aged sixteen, a delicatelooking and spare lad, was admitted on the 20 th of March, 1860. It appears that two years ago he had an attack of acute rheumatism, for which he was confined to bed for some weeks; all the joints of his body were affected, but he made no com. plaint of pain or uneasiness over the region of the heart. He is blind of the right eye from an injury received during childhood. At seven o'clock on the morning of admission, he was carrying home to his master some meat from market, when he suddenly staggered, and was obliged to catch hold of the railings for support. He became utterly helpless, was then conveyed to the hospital, and placed under Dr. Farre's care. On his admission, it was discovered that he had hemiplegia of the left side, with some rigidity of the leg, but not of the arm there was no loss of intelligence nor of speech. The carotids were acting most powerfully, with great pulsation in the neck. On examining the heart, the organ was found to be hypertro phied, with a direct systolic murmur, and a double murmur was heard with both sounds over the aorta. There was, besides these symptoms, a good deal of pain in the head. He was at once blistered at the nape of the neck, six leeches were applied behind the ear, and three grains of calomel were ordered at night.

March 22nd. - The pain in the head has gone, although the pulsations in the carotid arteries are still strong. He was ordered half an ounce of the infusion of digitalis three times a day. This not only diminished the excessive action of the heart, but next day permitted of some movement of the affected $\mathrm{leg}$, and on the 26 th the rigidity had completely disappeared. The infusion of digitalis was now reduced to two drachms, with twenty minims of tincture of hyoscyamus three times a day. The patient now began to improve, and on the 2 nd of April he took the compound cinchona mixture, with two grains of iodide of potassium, three times a day.

April 6th. - When standing up he can move the affected leg. 9th. -Great pulsation in the vessels generally, but particu. larly in those of the arm, which beat with a thrilling sensation. The digital arteries beat as strongly as an ordinary radial artery at the wrist. Besides his other treatment, he is having electricity applied every second day with considerable benefit.

16th. - Slowly improving. Ordered a mixture containing quinine three times a day.

23rd. - Can walk a little without assistance, and is otherwise much improved in his general health. He can move both his leg and arm very much better; the leg can be drawn up in bed, but he cannot grasp with the affected arm. There is still a double friction sound, and a double valvular murmur. The pulse is that clearly indicating regurgitant mitral valvular dis. ease. His intelligence is perfect. The galvanism is applied three times a week, and the quinine mixture is continued.

May 7th.-Heart symptoms as before; is sitting up, and walks with considerable dragging of the affected leg; his strength is much increased. Treatment continued, with wine.

\section{attediral Sorieties.}

\section{MEDICAL SOCIETY OF LONDON. \\ MoNday, April 30TH, 1860. Dr. Garrod, President. \\ ECZEMATOID ERUPTION FOLLOWING THE USE OF CHLOROFORM.}

MR. J. F. Clarke inquired if any Fellow of the Society had observed an eczematous eruption follow the inhalation of chloroform? A lady under the care of Mr. Curling and him. self had inhaled chloroform previous to an operation for fistula in ano. About three days afterwards the entire surface of the body was covered by a red papular eruption, attended by great irritation, but no other marks of constitutional disturbance. There was no sore-throat, and the tongue was natural. The eruption soon assumed a scaly character, the scales being 